\title{
EVALUATION OF MODIFIED IN SITU PINHOLE TECHNIQUE FOR CASTRATION IN HORSES
}

\author{
Mohamed Marzok ${ }^{1}$, Alaa Moustafa ${ }^{1}$, Nagwan El- Habashi ${ }^{2}$ \\ and Mohamed F. Abou-Elazab ${ }^{3}$ \\ ${ }^{1}$ Department of Surgery, Anesthesiology and Radiology, Faculty of Veterinary Medicine, \\ Kafrelsheikh University, Kafrelsheikh, El Geish street, 33516, Egypt. \\ ${ }^{2}$ Department of Pathology, Faculty of Veterinary Medicine, Kafrelsheikh University, \\ Kafr El-Sheikh, Egypt. \\ ${ }^{3}$ Department of Clinical Pathology, Faculty of Veterinary Medicine, Kafrelsheikh \\ University, Kafr El-Sheikh, Egypt.
}

\section{ABESTRACT}

A modified in Situ Pinhole technique (MPH) for castration in the horse was evaluated in a clinical trial. Plasma testosterone concentrations after challenge with human chorionic gonadotrophin (hCG), and histopathological changes of the testicular tissue were also assessed. Five stallions, aged 12-14 years, were castrated using MPH technique under general anaesthesia. The spermatic cords were double clamped and ligated. Both testes were left in situ. Testosterone concentrations were measured before, 2 months after castration, and immediately $1 \mathrm{~h}$ and $24 \mathrm{~h}$ after injection of 10,000 IU of hCG. Both testes from each castrate were collected at 2 months for histopathologic examination. MPH castration was successfully achieved. Moderated scrotal and preputial swelling was the only experienced short term complication. Testosterone concentrations were significantly lower than basal pre-operative levels at 2 months after castration, and did not respond to hCG. On histopathology, hyalinization of the seminiferous tubules and loss of testicular interstitial tissue were indicative of complete avascular necrosis. This 
modified primary closure castration technique of stallion is a simple practical method, with minimal postoperative complications; and could be safely advocated as an alternative to the traditional castration techniques allowing for second intention healing of scrotal wounds.

Key words: Horses, Castration, Wound

\section{INTRODUCTION}

Castration has been reported to be the most common routine surgical procedures in equines (Schumacher and Trotter, 1999). Castration has been used to control aggressive behaviour in the male horse, and as a surgical intervention to treat testicular neoplasia, orchitis, inguinal hernias, and torsion of the spermatic cord (Sheomaker et al., 2004). Several techniques have been described for equine castration: opened, closed and semi-closed (Searl et al., 1999). The open technique is most frequently used technique in equine practice (Trotter, 1988; Turner and Mcllwraith, 1989). The closed and semi-closed techniques have the disadvantage of requiring general anaesthetic, a risk in itself, as well as aseptic theatre facilities, advanced expertise and added expense (Cox, 1984; Trotter, 1988). Traditionally, castration techniques allow for second intention healing of scrotal wounds; however some have advocated primary closure (Barber, 1985) and (Palmer and Passmore, 1987). Other castration techniques have been described such as scrotal ablation (Misk and Seleim, 1987), followed by primary closure and laproscopic evolution and removal (Fischer and Vachon, 1992; Searl et al., 1999). 
The castration technique routinely used is based on secondintention healing of a scrotal wound, and the primary closure technique based on primary-intention healing of a scrotal wound has also been used. Five percent of the stallions castrated using the routine techniques have suffered from serious complications, such as severe haemorrhage and evisceration (Turner and Brown, 1993). These postoperative complications are the primary factor in malpractice claims against equine practitioners (Searl et al., 1999); therefore, the use of primary closure techniques has been encouraged. Closing of the castration incision requires minimal postoperative management and eliminates the majority of the recorded postoperative complications (Barber, 1985; Saifzadeh et al., 2008).

In all the techniques reported previously, testes were detached and removed. In situ castration technique is performed by rendering the testes non-functional in the scrotum by inducing ischemic necrosis of the testicular tissue through transection, ligation, and torsion or crushing of the spermatic cord using a prescrotal or inguinal incision or a laparoscopic method (Turner and Brown, 1993; Hickman et al., 1995; Wiemer, 1998; Pepe et al., 2005). The section- eligation-release (SLR) technique is a novel in situ castration technique in horses in which the ligation and transection of the spermatic cord is performed, rendering the testes non-functional in the scrotum (Saifzadeh et al., 2008; AbouAhmed et al., 2012). Also, the pinhole ( $\mathrm{PH})$ technique involving percutaneous spermatic cord ligation is another novel minimally invasive technique for in situ castration in bull calves (Ponvijay, 2007), donkeys (Badawy, 2009; Abou-Ahmed et al., 2012) and rams (Fazili et al., 2009), but this technique has not been evaluated in horses. 
The objective of this study was to describe a Modified in Situ Pinhole technique (MPH) as a primary closure method for castration in the horse by rendering the testes non-functional in situ. We hypothesized when testes are left in situ in the scrotum after ligation of the spermatic cord, the testes undergo ischemic necrosis. We assumed that the MPH technique would provide a simple, safe, and reliable method with minimal surgical trauma for castration of stallions with a reduction in post-operative complications compared with the standard traditional techniques of surgical castration.

\section{MATERIALS AND METHODS}

Five stallions aged 12-14 years, weighing $450-585 \mathrm{~kg}$, were used in this study. The stallions had a standard preoperative clinical examination including careful palpation of the external reproductive tract to confirm the presence of two normally descended scrotal testis. All stallions had normal vital signs, and normal haematological profile. All experimental procedures were reviewed and approved by the Animal Care Committee, Faculty of Veterinary Medicine, Kafrelsheikh University, in accordance with Egyptian ethical codes for studies on experimental animals. Food but not water was withheld for $12 \mathrm{~h}$ before surgery. Each stallion had received tetanus toxoid $\left(5 \times 10^{3} \mathrm{IU} /\right.$ intramuscular $)$. Castration was performed with the stallions anesthetized.

\section{Castration technique:}

All stallions were pre-medicated with xylazine hydrochloride $(0.5-$ $0.75 \mathrm{mg} / \mathrm{kg} \mathrm{IV})$, general anaesthesia were performed under deep narcosis induced using $10 \%$ chloral hydrate IV $(5 \mathrm{~g} / 50 \mathrm{~kg})$ together with ring block analgesia around the spermatic cord. All stallions were administered butorphanol tartrate $(0.03 \mathrm{mgkg}$, IM or IV) intra-

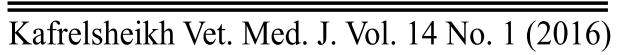


operatively to provide additional analgesia. Lactated Ringer solution (10$15 \mathrm{~mL} / \mathrm{kg} / \mathrm{hr}$, IV) was administered throughout the procedure. The stallions were positioned on right lateral recumbency with the upper hind leg tied cranially. The scrotal base was clipped and aseptically prepared for surgery. The Pinhole technique has been described in a recent study (Ponvijay, 2007; Badawy, 2009; Fazili et al., 2009; Abou-Ahmed et al., 2012). MPH technique has been described in Figure (1), at the level of the scrotal neck, the cord was grasped through the skin by placing the thumb on the caudal aspect and an index finger on the cranial aspect of the scrotal skin. The spermatic cord was retracted laterally and retained in that position by compressing the adjacent cranial and caudal skin of the scrotum together. A sterile flessa needle was introduced under the spermatic cord through the caudal scrotal skin, advanced cranially, and exited through the cranial scrotal skin. The needle is threaded with Nylon Self-Locking Cable Tie then pulled backward with Cable Tie. The spermatic cord was repositioned medially, and the needle was then reintroduced from the cranial scrotal skin hole and advanced caudally above the spermatic cord, thereby exiting through the previous caudal skin hole. The resulting Cable Tie formed a complete loop around the cord, with the free ends of the Cable Tie exiting through the caudal skin hole. Ligation of the spermatic cord was accomplished by tying the ends locking Cable Tie. Subsequently, the remaining strands were cut close to the skin, leaving the ischemic testes in the scrotum. The Nylon SelfLocking Cable Tie was left in situ and not removed. The surgical time was considered as the time elapsed from the initial needle penetration to suture cutting. The castrates were recovered in a padded recovery room. All castrates were allowed to hand walking for 30-45 min daily. No post operative medications were administrated to the castrates. 


\section{Blood collection and Testosterone assay:}

Blood samples were collected from each stallion from jugular vein immediately before, 2 months after castration, and immediately $1 \mathrm{~h}$ and $24 \mathrm{~h}$ after injection of 10,000 IU of human chorionic gonadotropin (HCG, Pregnyl; Nile Co. for Pharmaceuticals, Cairo, Egypt). Blood samples were collected into lithium heparin blood tubes. Plasma was obtained by centrifugation of blood samples at $1500 \mathrm{xg}$ for $20 \mathrm{~min}$. Plasma was immediately transferred into cryovials and stored at -20C until analysis. Plasma testosterone concentrations were measured by using a commercial ELISA kit (DRG Instruments, Marburg, Germany).

\section{Sampling and histopathology:}

Two months after castration, both testes of each castrate were removed by scrotal approach under deep general anaesthesia. Testes were fixed in a $10 \%$ neutral buffered formalin solution. The samples were dehydrated and embedded in paraffin wax; tissue sections at $3 \mu \mathrm{m}$ were stained with haematoxylin and eosin, and examined by light microscopy for histopathological analysis of the castration success.

\section{Statistical analysis:}

Data were treated by repeated measures analysis of variance (GLM procedure) followed by pair-wise comparisons among periods using the Bonferroni test. SPSS Version 16 for Windows, SPSS Inc., Chicago, IL, USA was used for analysis. $\mathrm{P}<0.05$ was considered statistically significant. is presented as the mean \pm standard deviation (St Dev) unless otherwise stated. 
Evaluation Of Modified In Situ Pinhole Technique For ...

Fig. (1): Intraoperative view of the Modified Pinhole castration technique.

Model illustrating spermatic cord ligation technique. (A) The spermatic cord enclosed by the left side scrotal skin at level of lateral side and the flessa needle is passed in a caudal to cranial direction adjacent the medial aspect of the spermatic cord; (B) Nylon Self-Locking Cable Tie is passed through the needle; (C) the needle is withdrawn backward leaving the suture in place; (D) the spermatic cord is repositioned on the medial side against the median raphe, causing the suture to form a hemi-loop. (E) The flessa needle is reintroduced from caudal to cranial through the original holes; $(\mathrm{F})$ the cranial end of the suture is reversed through the needle to exit caudally; (G) the flessa needle is withdrawn to have free ends of Nylon Self-Locking Cable Tie; (H) traction is applied to the Nylon Self-Locking Cable Tie ends so the suture is pulled through the skin against the spermatic cord; (I) the cord is ligated; and $(\mathbf{J})$ excess suture
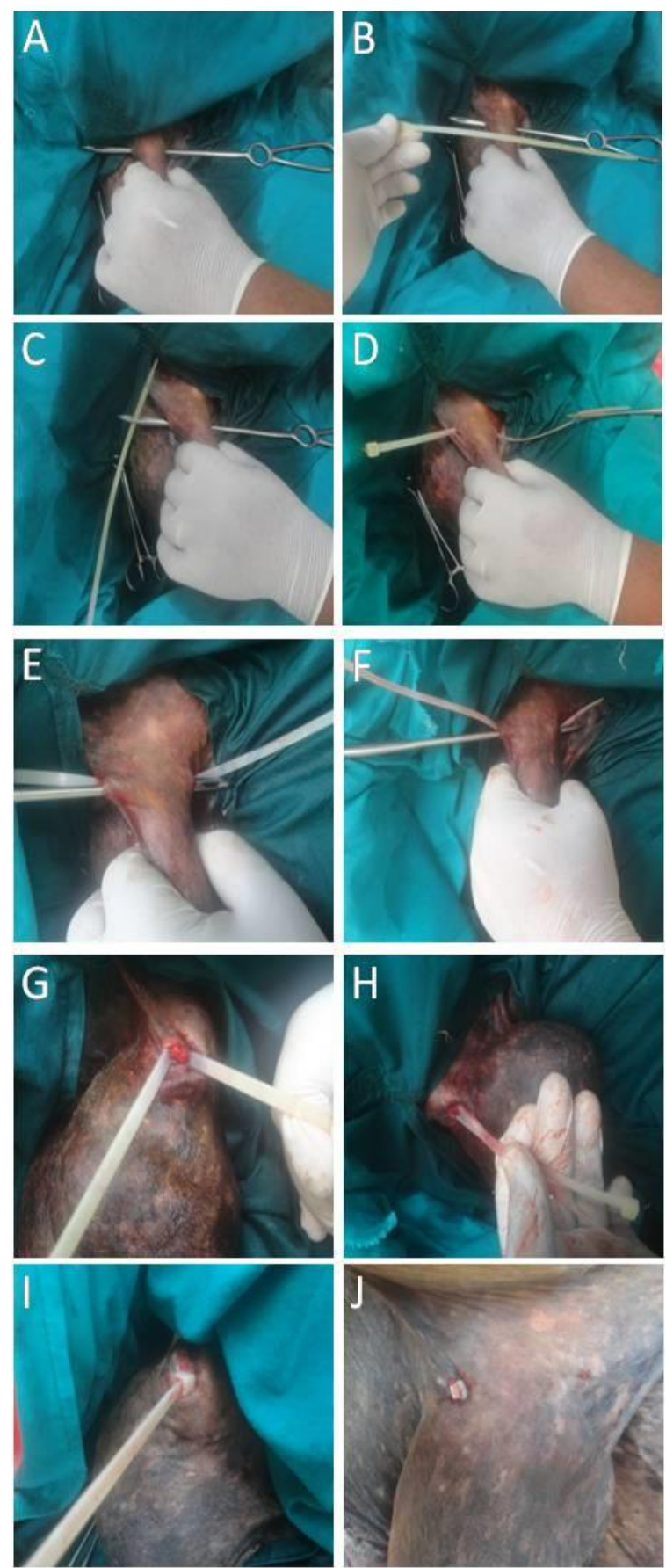
material is transected. 


\section{RESULTS}

The mean procedure duration in the anaesthetised stallion was 10.5 min (range, 9-14 min). None of the castrates showed any serous, sanguineous or purulent secretions from both the scrotal incisions. Wound healing took place uneventfully with no signs of dehiscence and resultant granulation.

\section{Testosterone assay:}

The testosterone concentrations after hCG challenge are depicted (Figure 2). The mean pre-operative serum testosterone concentration was $1.7 \mathrm{ng} / \mathrm{ml}$ (range, 1.46, $2.35 \mathrm{ng} / \mathrm{ml}$ ). All the castrates showed a significant $(\mathrm{p}<0.01)$ decrease in testosterone level 2 months after castration as compared to the pre-operative value $(0.76 \pm 0.26 \mathrm{ng} / \mathrm{ml}$ vs $1.7 \pm 0.24 \mathrm{ng} / \mathrm{ml}$ ). Following hCG administration, the concentrations of testosterone showed a slight, non significant increase on $1 \mathrm{~h}$ post treatment $(0.98 \pm 0.18 \mathrm{ng} / \mathrm{ml})$, and reached around the baseline value $(0.86 \pm 0.13 \mathrm{ng} / \mathrm{ml})$ after $24 \mathrm{~h}$.

Fig. (2): Effect of hCG administration the levels of testosterone in the castrates plasma (mean $\pm \mathrm{SD} ; \mathrm{n}=5$ ). The castrates showed a significant decrease in testosterone level 2 months after castration $(\mathrm{p}<0.01)$.

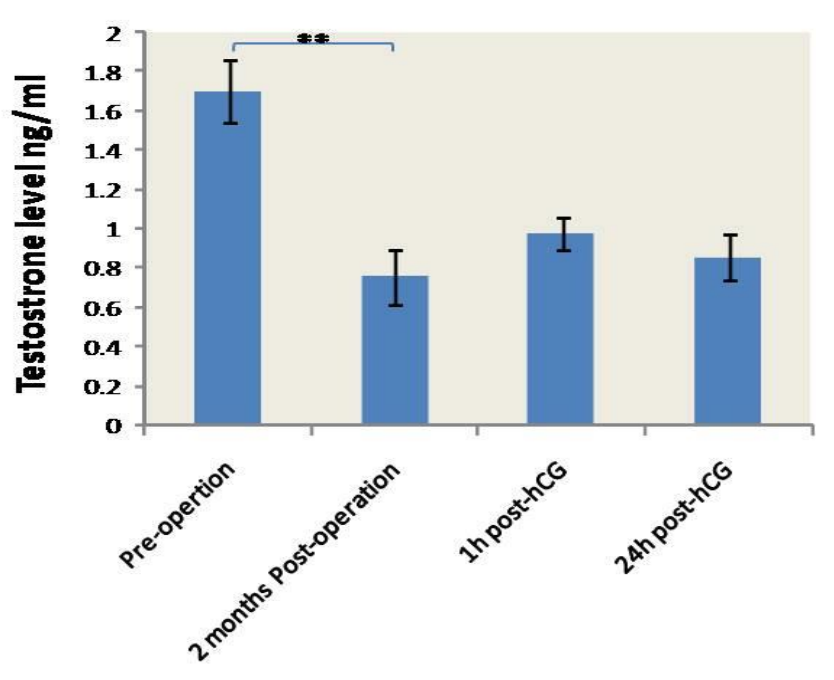

$\overline{\overline{\text { Kafrelsheikh Vet. Med. J. Vol. } 14 \text { No. } 1 \text { (2016) }}}$ 


\section{Histopathology:}

On gross examination, all epididymes appeared normal and all testes were markedly reduced in size. Histologically, testes showed marked coagulative necrosis in the whole layers of cells lining the seminiferous tubules (Figure 3, A and B) with absence of mature sperms in their lumen as well as leydig cells necrosis, increase in peritubular connective tissue and interstitial infiltrations by pigmented macrophages. The seminiferous tubules in few microscopic fields showed testicular degeneration of the fourth grade where seminiferous tubules were denuded of primary and secondary spermatocytes and spermatogonial cells (Figure 4). Mature sperms were completely absent in the lumen of seminiferous tubules. Interstitial lymphocytic cells infiltrations were also observed (Figure 5, A). There is a marked increase in peritubular connective tissue as shown in Figure 5, B.

Fig. (3): (A) Testis showing coagulative necrosis in the whole layers of cells lining the seminiferous tubules (black star) with absence of mature sperms in the lumen along with interstitial infiltrations by pigmented macrophages as well as interstitial connective tissue proliferation stained with hematoxylin and eosin, x200. (B) Higher magnification of figure 3 , $\mathrm{A}, \mathrm{x} 400$.

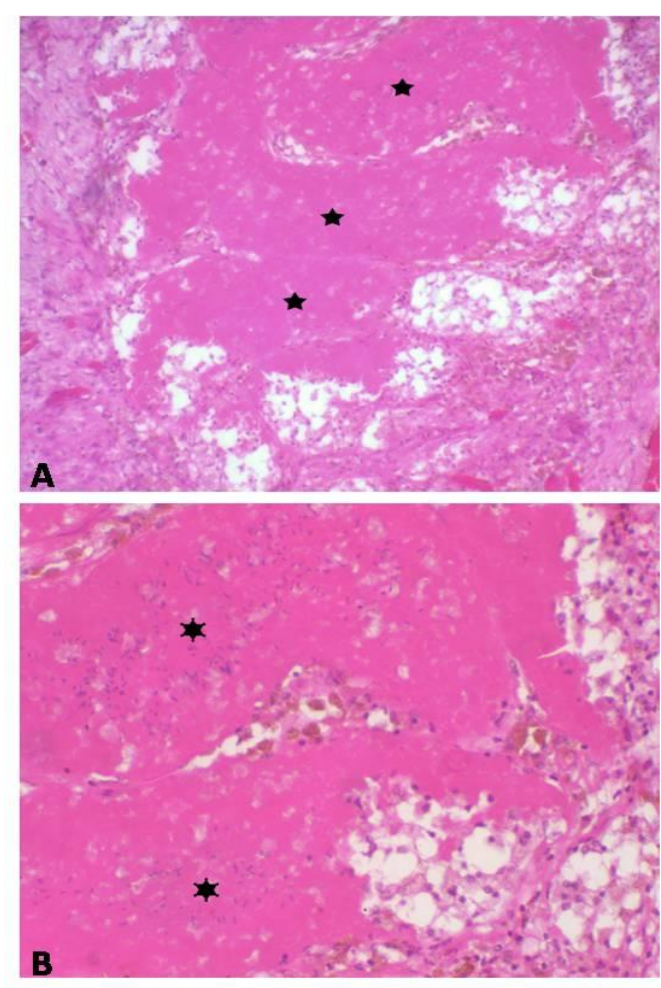

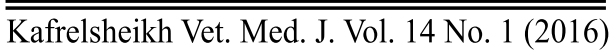


Fig. (4): Testis showing seminiferous tubules (black star) denuded of primary and secondary spermatocytes and spermatogonial cells as well as complete absence of mature sperms in their lumen together with intertubular connective tissue proliferation (head arrow) and leydig cells necrosis (thin arrow) stained with hematoxylin and eosin, $\mathrm{x} 100$.

Fig. (5): (A) Seminiferous tubules (black star) denuded of primary and secondary spermatocytes and spermatogonial cells as well as leydig cells necrosis (thick arrow) and lymphocytic cells infiltrations stained with hematoxylin and eosin, x200. (B) Seminiferous tubules showing intertubular connective tissue proliferation (arrow) and lymphocytic cells infiltrations, x200.

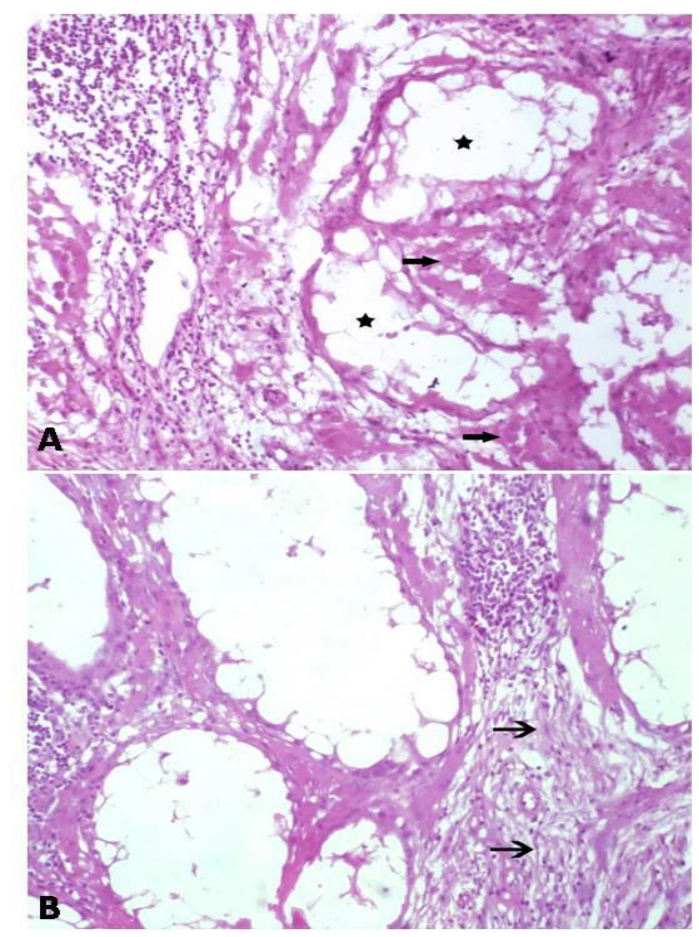

$\overline{\text { Kafrelsheikh Vet. Med. J. Vol. } 14 \text { No. } 1 \text { (2016) }}$ 


\section{DISCUSSION}

MPH castration technique was readily accomplished in anesthetized recumbent stallions. The spermatic cord was easily recognized, and occluded through two skin holes at scrotal neck without major complications. This study is describing a primary intention healing technique for surgical castration of stallions rendering testes nonfunctional in the scrotum owing to ischemia while leaving the testes in the scrotum. Ischemic necrosis or infarction of the testes is induced by blockage or prevention of blood flow to the testes. This technique is a minimally invasive procedure characterized by minimal intra or postoperative complications associated with a routine technique (e.g., haemorrhages and evisceration). Asepsis is essential with this technique because introduction of infection into a scrotal cavity would result in severe complications (Kent et al., 1996; Searle et al., 1999).

MPH castration technique has not been used in horses as an alternative to other conventional methods. For this reason, the present study was designed to evaluate minimally invasive in situ technique for sterilizing horses. PH technique has been evaluated in the castration of calves (Ponvijay, 2007) and rams (Fazili et al., 2009) and donkeys (Badawy, 2009; Abou-Ahmed et al., 2012) but not in horses.

Ponvijay (2007) described pinhole castration, a novel minimally invasive technique for in situ castration of bull calves, and proposed the technique be readily adaptable in larger animals with thicker spermatic cords, e.g. horses. MPH technique, as evaluated in the present study, proved to be a safe and fairly quick method for castrating stallions through scrotal neck percutaneous ligation followed by primary closure of the skin. 
In the present study the histopathological findings showed, severe testicular degeneration, fibrosis, hyalinization and coagulative necrosis of the seminefrous tubules. These might be attributed to ligation of the spermatic cord and the ligated testes remained in the scrotum for 2 months before their removal and collection for histopathological examination, a considerable time sufficient for complete ischemia and necrosis. Smith (1955) showed that after $4 \mathrm{~h}$ of induced testicular ischemia in dogs, spermatogenesis had ceased and in some testicles the Sertoli and the Leydig cells were also damaged, while 10h or more of ischemia resulted in elimination of all Leydig cells; and the testicular elements were replaced by connective tissue. It was demonstrated in dogs, that after 12 days of vascular occlusion, seminiferous tubules were replaced by an 'amorphous mass' and had no basement membrane. Leydig cells at this time had become atrophied (Dixit, 1977). In some studies, marked testicular degeneration was noted after ischemia for 60 min in the rat (Carmignani et al., 1983; Costentino et al., 1986). The testicular necrosis in the castrates are thus in agreement with the previous observations. In the present study, vascular occlusion blocked up the blood flow to the testicles producing testicular necrosis as a result of the hypoxia. An inevitable ischemic necrosis or infarction of the testicles is produced when occlusion of the arterial supply of the tissue occurs (Slauson and Cooper, 2002). Application of the ligatures of the spermatic cord apparently impeded the blood flow to the testes with a subsequent quick hypoxia response of the testicular cells ending in coagulative necrosis.

Ligation of the spermatic cord induced necrosis of the testicular tissue as shown by plasma testosterone concentrations 2 months after surgery. Endocrine analysis provides a useful non-invasive technique for

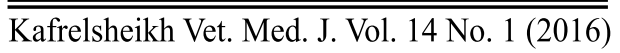


determining the presence of testicular tissue in suspect cryptorchids and questionable animals (Morrow 1986; St Jean et al., 1992; Cox, 1993). The hCG stimulation test is common practice in cases of equine cryptorchidism with the observed increase in testosterone concentration in animals with testicular tissue being thought to result in increased diagnostic accuracy of endocrine testing (Cox, 1993). Stimulation of Leydig cells with hCG has been widely used and is often considered the gold standard (McEachern et al., 2004). The test is based on the Leydig cell elaboration of testosterone in increased amounts in response to the injection of hCG (Morrow, 1986). In the present study no significant changes in testosterone concentrations were detected in the castrates, thus the post-hCG stimulation testosterone concentrations could be in consistent with successful sterilization.

The most common complications following traditional castration of horses are excessive swelling, haemorrhage, incisional infection, scirrhous cords and eventration (Hunt, 1991). The technique reported here, was associated with minimal complications. The MPH technique was associated with moderate scrotal and preputial swelling, reached the highest point on day 3 post-operative. Some preputial and scrotal oedema is normal, usually greatest 3 to 6 days after castration and subsiding by 9 days (Hunt, 1991).

Based on the results of testosterone concentration assay and histopathological evaluation of MPH ligation technique of spermatic cord presented in this study, the technique proved to be simple, quick, efficient and reliable with no need for postoperative care. The technique was associated with minimal complications and could be brought into consideration as an alternative to conventional Horses castration methods without scrotal wound. 


\section{REFERENCES}

- Abou-Ahmed H, EL-Kammar M, EL-Neweshy M, Abdel-Wahed R (2012): Comparative Evaluation of Three In Situ Castration Techniques for Sterilizing Donkeys: Incision-Ligation (a Novel Technique), Section-Ligation-Release, and Pinhole. Journal of Equine Veterinary Science (32), 711-718.

- Badawy A (2009): Percutaneous Ligation of Spermatic Cord as an Alternative to Opened Castration in Donkeys. Benha Vet. Med., J. Vol. 20, No2.

- Barber $S$ (1985). Castration of horses with primary closure and scrotal; ablation. Vet Surg ;14: 2-6.

- Carmignani G, Tedde G, deStefani S, Montella A, Maffezzini M, (1983): An experimental study of the effect of ischemia on testicular structure in the rat: efficacy of intravenous inosine. J Androl 4, 378386.

- Costentino MJ, Nishida M, Rabinowitz R, Cockett ATK (1986): Histopathology of prepubertal rat testes subjected to various durations of spermatic cord tension. J Androl 7, 23-31.

- Cox JE (1984): Castration of horses and donkeys with first intention healing .Veterinary Record 115:372-375.

- Cox JE (1993): Cryptorchid castration. In: McKinnon AO, Voss JL (eds), Equine Reproduction. Lea and Febiger, Philadelphia, pp. 915-921. 
- Dixit VP (1977): Histological and biochemical changes produced in the dog testis after vascular occlusion. Ind J Med Res 65, 76-81.

- Fazili MR, Bhattacharyya HK, Buchoo BA, Kirmani MA, Dirazi MM, Khan I (2009). Evaluation of pinhole castration technique in rams. Small Ruminant Res;84:61-4.

- Fischer A, Vachon A (1992): Laproscopic cryptorchidectomy in horses .J. Am. Vet. Med. Assoc., 201(11):1705-1708.

- Hickman J, Houlton J, Edwards B (1995). An atlas of veterinary surgery $3^{\text {rd }}$ ed. Oxford, UK: Blackwell Science.

- Hunt RJ (1991): Management of complications associated with equine castration. Compend Cont Educ Pract Vet 13, 1835- 1841.

- Kent JE, Thrusfield MV, Robertson IS (1996): Castration of calves: a study of methods used by farmers in the United Kingdom. Vet Record 138:384-397.

- McEachern R, Houle AM, Garel L, Van Vliet G (2004): Lost and found testes: the importance of the hCG stimulation test and other testicular markers to confirm a surgical declaration of anorchia. Horm Res 62, 124-128.

- Misk N, Seleim M (1987): An improved technique for castrating equids. Vet. Record 115:372-375.

- Morrow DA (1986): Current therapy in theriogenelogy, $2^{\text {nd }}$ edn. W.B.Saunders, Philadelphia, pp. 749-750. 
- Palmer S, Passmore J (1987): Midline scrotal ablation technique for unilateral cryptorchid castration in horses. J Am Vet. Med. Assoc. 190(3):283-285.

- Pepe M, Gialletti R, Moriconi F, Puccetti M, Nannarone S, Singer E (2005). Laparoscopic sterilization of Sardinia donkeys using an endoscopic stapler. Vet Surg;34:260-4.

- Ponvijay KS (2007). Pinhole castration: a novel minimally invasive technique for in situ spermatic cord ligation. Vet Surg;36:74-9.

- Saifzadeh S, Hobbenaghi R, Asri-Rezaei S, Shokouhi SJ, Naghadeh B, Rohi SM (2008). Evaluation of section ligation release (SLR) technique devised for castration in the stallion. Repord Dom Anim; 43:678-84.

- Schumacher J, Trotter GW (1999). Complication associated with castration in horse. In practice; 21:298-307.

- Searl D, Dart AJ, Dart CM (1999): Equine castration: review of anatomy, approaches, techniques and complications in normal, cryptorchid and monorchid horses. Aust Vet J 77:428-434.

- Sheomaker R, Bailey J, JanZen E, Wilson DG (2004). Routine castration in 568 draught colts: incidence of evisceration and omental herniation. Equine Vet J;36:336-40.

- Slauson DO, Cooper BJ (2002): Mechanisms of Disease, $3^{\text {rd }}$ edn. Mosby, St Louis, pp. 120-124. 
- Smith GI (1955): Cellular changes from graded testicular ischemia. J Urol 73, 355362.

- St Jean G, Gaughan E, Constable P (1992): Cryptorchidism in North American cattle: breed predisposition and clinical findings. Theriog $38,951-958$.

- Trotter $G$ (1988): Normal and cryptorchid castration. Veterinary Clinics of North America: Equine Pracatice 4(3): 493-513.

- Turner A,Mcllwraith C (1989) : Castration In: Techniques In Large Animal Surgery. Lea and Febiger, Philadelphia, pp: 177-191.

- Turner TT, Brown KJ (1993). Spermatic cord torsion: Loss of spermatogenesis despite return blood flow. Biol Reprod;49:401-7.

- Wiemer $P$ (1998). Experience with spermatic cord ligation as a method of castration in the stallion. The surgical castration of the testicle in situ appears to be of value. Tijdschr Diergeneeskd; $123: 432-4$. 